\title{
Understanding how women's groups improve maternal and newborn health in Makwanpur, Nepal: a qualitative study
}

\author{
J. Morrison ${ }^{\mathrm{a}, *}$, R. Thapa ${ }^{\mathrm{b}}$, S. Hartley ${ }^{\mathrm{a}}$, D. Osrin ${ }^{\mathrm{a}}$, M. Manandhar $^{\mathrm{b}}, \mathrm{K}$. Tumbahangphe ${ }^{\mathrm{b}}$, \\ R. Neupane ${ }^{b}$, B. Budhathoki ${ }^{b}$, A. Sen ${ }^{b}$, N. Pace ${ }^{b}$, D.S. Manandhar ${ }^{b}$, A. Costello $^{a}$ \\ a UCL Centre for International Health and Development, Institute of Child Health, University College London, 30 Guilford Street, London WC1N 1EH, UK \\ b Mother and Infant Research Activities (MIRA), PO Box 921, Kathmandu, Nepal
}

\section{A R T I C L E I N F O}

\section{Article history:}

Received 18 August 2009

Accepted 27 November 2009

\section{Keywords:}

Neonatal

Women

Qualitative research

Process evaluation

Community

Nepal

\begin{abstract}
A B S T R A C T
Women's groups, working through participatory learning and action, can improve maternal and newborn survival. We describe how they stimulated change in rural Nepal and the factors influencing their effectiveness. We collected data from 19 women's group members, 2 group facilitators, 16 health volunteers, 2 community leaders, 21 local men, and 23 women not attending the women's groups, through semi-structured interviews, group interviews, focus group discussions and unstructured observation of groups. Participants took photographs of their locality for discussion in focus groups using photoelicitation methods. Framework analysis procedures were used, and data fed back to respondents. When group members were compared with 11184 women who had recently delivered, we found that they were of similar socioeconomic status, despite the context of poverty, and caste inequalities. Four mechanisms explain the women's group impact on health outcomes: the groups learned about health, developed confidence, disseminated information in their communities, and built community capacity to take action. Women's groups enable the development of a broader understanding of health problems, and build community capacity to bring health and development benefit.
\end{abstract}

(c) 2009 Royal Society of Tropical Medicine and Hygiene. Published by Elsevier Ltd. All rights reserved.

\section{Introduction}

In Asia, neonatal deaths account for three-quarters of infant mortality and more than half of under-five's deaths. ${ }^{1}$ Nepal's neonatal mortality rate is among the highest in Asia, at 33 per 1000 live births. Most births (81\%) occur at home, and both community interventions and health service improvements are necessary to increase child survival. ${ }^{2}$ In 2004, we published the results of a cluster randomised controlled trial testing the effect of a participatory intervention with women's groups on neona-

\footnotetext{
* Corresponding author. Tel.: +44 207905 2261/2883; fax: +442074042062 .

E-mail address: j.morrison@ich.ucl.ac.uk (J. Morrison).
}

tal mortality. ${ }^{3}$ We employed 12 local women, who were not health workers, to convene 111 women's groups covering a rural population of 80 000. Groups met monthly to discuss issues affecting maternal and newborn health, and completed a community action cycle of problem identification, planning and participatory evaluation. ${ }^{4}$ Group members usually lived near the meeting location, were married and attended regularly-despite the fact that groups were open to any woman. From 2001 to 2003, we observed a $30 \%$ reduction in neonatal mortality and a substantial reduction in maternal mortality compared with control areas. Women in intervention clusters were more likely to have antenatal care and hygienic practices, and there were smaller effects on institutional delivery and trained birth attendance (Table 1). Population surveillance continued from 2003 to 2008 and 
Table 1

Effectiveness of the women's group intervention on care behaviours.

\begin{tabular}{|c|c|c|c|c|c|}
\hline & \multicolumn{2}{|c|}{ Intervention } & \multirow{2}{*}{$\frac{\text { Control }}{n}$} & \multirow[b]{2}{*}{$\%$} & \multirow[t]{2}{*}{ Adjusted odds ratio $(95 \% \mathrm{CI})$} \\
\hline & $n$ & $\%$ & & & \\
\hline Pregnancies & 3190 & $\%$ & 3524 & $\%$ & \\
\hline Any antenatal care & 1747 & 55 & 1051 & 30 & $2.82(1.41-5.62)$ \\
\hline Deliveries & 2945 & & 3270 & & \\
\hline Institutional deliveries & 201 & 7 & 66 & 2 & $3.55(1.56-8.05)$ \\
\hline Birth attended by government health provider & 272 & 9 & 102 & 3 & $3.12(1.62-6.03)$ \\
\hline Used a boiled blade to cut the cord & 1580 & 54 & 827 & 25 & $3.47(1.39-8.69)$ \\
\hline Attendant washed her hands & 1988 & 68 & 1064 & 33 & $5.5(2.40-12.6)$ \\
\hline
\end{tabular}

the intervention was introduced into control areas in 2005.

Randomised controlled trials are generally considered the most rigorous way to evaluate the efficacy of an intervention, but they cannot explain trial results or examine their external validity. Concurrent process evaluations, especially for complex interventions, may address these issues by offering information on social context, the content and implementation of the intervention, and the perceptions of different participants. ${ }^{5}$

The Makwanpur intervention was developed from a Bolivian project where women were not usually involved in decision making, and the cost of maternity care-seeking was high. Key features were an organisational commitment to a participatory learning and action approach (PLA), and the overall aim of women's empowerment. ${ }^{6}$ In Nepal, women met monthly, and a facilitator led them through a participatory action cycle. ${ }^{4,7}$ The intervention borrowed from the literature on participatory approaches to community development, and the ideas of Paulo Freire, who argued that sustainable social change is only possible if teachers and learners engage in a dialogue, exchanging ideas and experiences..$^{8,9}$ In Nepal, it was hoped that exchange within communities would enable a critical awareness of environmental, economic and social constraints to health improvement and communities would be motivated to act to improve their situation. This is different from traditional health education interventions that focus on transmission and learning of technical 'messages'. The women's group participatory learning and action intervention is described in more detail elsewhere. ${ }^{4}$

Although participatory learning and action (PLA) methods are widely used in the development field, the Nepal Makwanpur study is the only published randomised controlled trial to provide evidence that PLA interventions improve health outcomes. We present a qualitative evaluation of how the intervention may have brought about health and non-health benefits. We considered community views of the group process, and the effect of the sociopolitical context on the implementation of the intervention and the community response.

\section{Methods}

\subsection{Location}

The trial involved 24 village development committee areas in Makwanpur district, covering a population of 170000 living in 1600 square kilometres of hill and plains. ${ }^{10}$ Details of the trial and the study population have been described previously. ${ }^{11-13}$ Data on group attendance and socioeconomic status were also obtained from 11 184 women who had recently given birth through the ongoing surveillance system described in the trial paper. The women's group intervention was implemented by Mother and Infant Research Activities (MIRA), a Nepalese non-governmental research organisation. We purposively sampled two areas that had women's groups. One area had a more active group and the other a less active group. We also chose an area without a group. The three study areas were relatively secure and less affected by the Maoist insurgency. They had differing topography and were several hours walk from a road or health facility.

\subsection{Data collection methods}

Data were collected in Nepali by two Nepalese researchers who had experience and training in qualitative research methods. In six weeks, researchers piloted topic guides, photoelicitation, and other methods, which informed planning of appropriate data collection methods with different groups. We piloted in areas where data were not collected. We conducted focus group discussions and group interviews with women's group members ( 2 groups, 19 participants), women who did not attend the group (4 groups, 23 participants), mothers-in-law (2 groups, 10 participants), men (3 groups, 21 participants), and community health volunteers ( 1 interview, 2 groups, 16 participants). Methods evolved to respond to the challenges of collecting data in a scattered population. We also interviewed women's group facilitators and community leaders in the qualitative study areas, and conducted observations of women's group meetings (Table 2). Photoelicitation was used to facilitate discussion in focus groups with women's groups, men, and women who did not attend groups. ${ }^{14-16}$ Piloting informed the selection of respondents to the photoelicitation method. Semi-structured interviews were completed with community leaders, community health workers and women's group facilitators. Discussions and interviews were usually around two hours in duration. Respondents were accessed by researchers making houseto-house visits. Data were tape recorded, transcribed and translated into English. Unstructured observations of group meetings were conducted and notes translated into English. We collected socioeconomic data from 11 184 women interviewed six weeks after the birth of their babies in the 24 village development committee areas of 
Table 2

Study participants and sampling criteria.

\begin{tabular}{|c|c|c|c|}
\hline Area & 1 ward of VDC 1 & 1 ward of VDC 2 & 1 ward of VDC 3 \\
\hline Allocation & Intervention & Intervention & Control \\
\hline Status of group & Active & Less active & No group \\
\hline Topography & Plains & Hill & Hill \\
\hline \multirow[t]{10}{*}{ Method and sample } & Community Health Volunteer SSI (1) & Community Health Volunteer FGD (1) & $\begin{array}{l}\text { Community Health } \\
\text { Volunteer FGD (1) }\end{array}$ \\
\hline & Women's group members FGD $\left(2^{\mathrm{a}}\right)$ & & $\begin{array}{l}\text { Group interviews } \\
\text { with village } \\
\text { women }\left(2^{\mathrm{a}}\right)\end{array}$ \\
\hline & \multicolumn{2}{|c|}{ Women's group member observations (2) } & \\
\hline & \multicolumn{2}{|c|}{ Men FGD $\left(2^{\mathrm{a}}\right)$} & Men FGD $\left(1^{\mathrm{a}}\right)$ \\
\hline & \multicolumn{2}{|c|}{ Village Health Worker SSI (2) } & \\
\hline & \multicolumn{2}{|c|}{ Maternal and Child Health Worker SSI (2) } & \\
\hline & \multicolumn{2}{|c|}{ Mothers-in-law FGD (2) } & \\
\hline & \multicolumn{2}{|c|}{ Women not attending groups FGD ( $\left.2^{\mathrm{a}}\right)$} & \\
\hline & \multicolumn{2}{|c|}{ Women's group facilitator SSI (2) } & \\
\hline & \multicolumn{2}{|c|}{ Community leader SSI (2) } & \\
\hline
\end{tabular}

FGD: focus group discussion; SSI: semi-structured interview; VDC: Village Development Committee.

a Focus group discussions conducted using photoelicitation methods.

the Makwanpur trial. ${ }^{3}$ The women were asked whether they had attended a MIRA women's group, and data were compared for group and non-group members. Data were entered and analysed in STATA 10 (Stata Corp., College Station, TX, USA).

\subsection{Photoelicitation}

We used photoelicitation in discussions to help respondents communicate their experiences. Photoelicitation has been utilised particularly in research with marginalised groups. ${ }^{17-24,25}$ A lack of 'verbal fluency' among marginalised populations can make photographs a good way to concretise issues to correspond more closely to the thinking of respondents. Focus group discussion participants were requested to take photographs with disposable cameras, which would be discussed with the group. Participants decided how the disposable cameras would be distributed and were taught how to use them. In these focus groups we distributed three cameras, each with 27 photographs. Participants were asked to take photographs of three subjects: health, MIRA (the intervention implementer), and the social environment. They were invited to take photographs of anything that was important to them, helped them describe something, or represented something they were unable to photograph. We collected cameras after one or two weeks and developed two copies of the photographs. Participants received the photographs and the negatives, and one copy was retained by researchers.

In the focus group, participants were asked how they felt about taking photographs, any issues that arose, and if there was anything they wished to discuss that they were unable to photograph. Participants split into smaller groups, sorted the photographs into the three categories, and chose photographs for discussion. We also identified interesting photographs, or ones that necessitated description by participants. Discussions began with the participants' choice of topic.

Translated data from focus group discussions were imported into NVIVO (QSR International Pty Ltd, Victo- ria 3108, Australia) and analysed using the framework method. ${ }^{26}$ There was consensus in themes generated by an independent researcher and JM, and feedback of thematic analysis to five groups of respondents informed data interpretation.

\section{Results}

The socioeconomic status and ethnicity of pregnant women who joined the groups was broadly similar to women who did not join the groups. Group members were slightly poorer in terms of assets, household construction, and access to a protected water supply, but had better education, reading skills, and land ownership (Table 3). Qualitative data were analysed to describe the context of the lives of women and their families in Makwanpur and to help explain the results of the trial. Four key mechanisms were identified: the groups learned, developed confidence, disseminated information within communities, and increased community capacity to take action.

\subsection{The context of women's lives in Makwanpur}

Table 4 provides verbatim evidence on several important contextual factors in women's lives: poverty, gender roles, the political conflict arising from the Maoist insurgency in Nepal (2004-2006), and the mistrust of local health services.

Most of the population were Buddhists of Tamang ethnicity, whose first language is Tamang. Many women had arranged marriages, and inter-caste marriages were rare. After marriage, women usually moved to their husband's homes, and mothers-in-law were major household decision makers. Families were mainly engaged in agriculture, but during less busy seasons, many men worked outside the home, doing manual labour in towns, the capital city, Kathmandu, or abroad. Women were engaged in cooking, making alcohol, cleaning, collecting water and fodder, looking after children and animals, and tending crops. Respondents expressed their desire to progress economically and to move to a more prosperous place, but 
Table 3

Socioeconomic status of women's group members among pregnant women in the study area from 2001 to 2008

\begin{tabular}{|c|c|c|}
\hline & \multicolumn{2}{|c|}{ Women's group member ${ }^{*}$} \\
\hline & No & Yes \\
\hline Number of pregnant women (total 11 184) & $8911(79.7 \%)$ & $2273(20.3 \%)$ \\
\hline Age at marriage (years): mean (SD) & $17.4(2.8)$ & $17.1(2.5)$ \\
\hline \multicolumn{2}{|l|}{ Higher castes } & $\%$ \\
\hline Brahmin-Chhetri & 14.3 & 16.0 \\
\hline \multicolumn{3}{|l|}{ Tibeto-Burman castes } \\
\hline Tamang & 68.1 & 63.0 \\
\hline Magar & 3.8 & 5.3 \\
\hline Others (including lower castes) & 13.8 & 15.7 \\
\hline \multicolumn{3}{|l|}{ Education } \\
\hline None & 65.0 & 61.7 \\
\hline Primary & 20.3 & 21.5 \\
\hline Secondary & 14.7 & 16.8 \\
\hline Literate & 28.4 & 31.8 \\
\hline Women who had had a previous pregnancy & 69.3 & 75.9 \\
\hline Number of people in household: mean (SD) & $7.2(3.3)$ & $7.3(3)$ \\
\hline Total land owned $^{* *}$ (acres): mean (SD) & $1.4(1.2)$ & $1.5(1.6)$ \\
\hline \multicolumn{3}{|l|}{ Assets } \\
\hline Electricity & 46.3 & 45.7 \\
\hline Radio & 64.0 & 50.0 \\
\hline Television & 16.9 & 18.3 \\
\hline Bicycle & 6.8 & 5.9 \\
\hline Telephone & 3.1 & 4.7 \\
\hline \multicolumn{3}{|l|}{ Household construction materials } \\
\hline Cement and bricks, mud and bricks & 7.9 & 5.4 \\
\hline Mud and stone & 58.2 & 63.8 \\
\hline Planks, thatch or other & 33.9 & 30.8 \\
\hline \multicolumn{3}{|l|}{ Source of drinking water } \\
\hline Piped & 11.9 & 8.5 \\
\hline Well, yard well, public well & 20.5 & 15.3 \\
\hline River, other & 70.8 & 78.5 \\
\hline \multicolumn{3}{|l|}{ Main occupation in household } \\
\hline Agriculture & 92.7 & 94.0 \\
\hline Waged labour & 4.1 & 3.0 \\
\hline Government job & 1.6 & 1.5 \\
\hline Small business & 1.6 & 1.5 \\
\hline
\end{tabular}

\footnotetext{
* If a woman attended a group at least once she is recorded as a 'yes'.

** Total land is the sum of dry and wet land. It was originally measured in khatta (the Nepali unit of measurement for area) and then converted into acres.
}

opportunities for this were limited because land prices were low and terrain prone to landslides or floods. Access to water was also a problem and some households did not own their own land.

Many respondents, particularly women, felt that there was some positive social change in their communities, which was often linked to interactions with trustworthy non-governmental organisations (including MIRA). All types of respondents felt that discrimination against girls was decreasing, and there was increasing pluralism in health care seeking behaviour. Yet gender roles were still highly segregated, and there were reports of domestic violence against women. Some felt that the illegal practice of polygamy was oppressive and prevented women's development. Social problems like gambling and alcoholism were often the catalyst for domestic violence or retribution attacks by Maoists. Although the study areas were relatively secure, the insurgency made some respondents fearful to move around at night and gather in groups. National strikes and army patrols sometimes restricted access to health services.

Ethnicity and caste were important elements of the social context. There was some evidence of discrimination on the basis of ethnicity, yet it was not explicitly discussed. Respondents felt that homogeneity of ethnicity was a hindrance to social and economic development. When communities are ethnically mixed, more ideas are discussed and villagers become more motivated to work for change.

Mistrust of local government health services was ubiquitous and all respondents expressed their dissatisfaction. There was a lack of trust in the quality and appropriateness of the medicine provided, doubt in the skills of health personnel, and suspicion about misuse of funds. Community members also felt they were often not treated well when visiting local health facilities. Respondents preferred 
Table 4

The context of women's lives in Makwanpur.

\begin{tabular}{|c|c|c|}
\hline Contextual factor & Evidence & Respondent and method \\
\hline \multirow[t]{2}{*}{ Poverty } & $\begin{array}{l}\text { 'Even to have a meal twice a day is difficult, we } \\
\text { have no time to rest, even in the house.' }\end{array}$ & Men, FGD \\
\hline & $\begin{array}{l}\text { 'I don't have good farm land, which is necessary } \\
\text { to survive. This place is full of sorrow.' }\end{array}$ & Mother in law, FGD \\
\hline Gender roles & $\begin{array}{l}\text { 'Who gives money for our household work? } \\
\text { No-one sees our work.' }\end{array}$ & Women's group member, FGD \\
\hline Social change & $\begin{array}{l}\text { 'Right now there is no discrimination, there } \\
\text { was a lot of discrimination before'... 'We } \\
\text { didn't have the chance to study before because } \\
\text { of discrimination.' }\end{array}$ & Women's group member, FGD \\
\hline Social change associated with NGOs & $\begin{array}{l}\text { 'Organisations help... it is good in comparison } \\
\text { with before.' }\end{array}$ & Health worker, SSI \\
\hline \multirow{2}{*}{ Violence and insurgency } & 'He often beat his wife because he was drunk.' & Health worker, SSI \\
\hline & $\begin{array}{l}\text { 'The Maoists found out ... and in revenge } \\
\text { they... punished him by breaking his hands } \\
\text { and legs.' }\end{array}$ & Health worker, SSI \\
\hline \multirow[t]{3}{*}{ Ethnicity and caste } & $\begin{array}{l}\text { 'Where there are a mix of castes, people } \\
\text { understand properly' }\end{array}$ & Facilitator, SSI \\
\hline & 'If Bhote and Chepang (marginalised groups) & Health volunteer, FGD \\
\hline & $\begin{array}{l}\text { had come, then I would have asked them to } \\
\text { clean the cattle dung.' }\end{array}$ & \\
\hline \multirow[t]{3}{*}{ Mistrust of local health services } & $\begin{array}{l}\text { 'Date expired medicine are provided which } \\
\text { make the patient more sick' }\end{array}$ & Women not attending group, FGD \\
\hline & 'I think doctors give medicine by guessing' & Men, FGD \\
\hline & $\begin{array}{l}\text { 'If we have money we go to the medical shop } \\
\text { or we go to (the district centre)' }\end{array}$ & Women not attending group, FGD \\
\hline Increased knowledge of identity of health volunteers & $\begin{array}{l}\text { 'We only found out who the FCHV and TBA } \\
\text { were after the meetings started.' }\end{array}$ & Women's group member, FGD \\
\hline Pluralism & $\begin{array}{l}\text { 'The patient is shown to the shaman for } \\
\text { treatment, and if they do not recover, then } \\
\text { they are taken down to the medical (shop)' }\end{array}$ & Men, FGD \\
\hline
\end{tabular}

FGD: focus group discussion; SSI: semi-structured interview; FCHV: Female Community Health Volunteer; TBA: Traditional Birth attendant.

traditional healers, private practitioners, and pharmacies. No respondent photographed a government health service provider, but many photographed other types of provider. Health workers were aware of community dissatisfaction, yet felt unable to address their concerns and provide services that were perceived as giving value for money. There was some evidence that communities with women's groups became more aware of the identity of the local female health volunteer, and health volunteers participated actively in around $75 \%$ of groups, but overall, there was little evidence that health services improved as a result of the intervention.

Figure 1a-e illustrates aspects of local women's lives photographed by respondents.

\subsection{Mechanisms by which women's groups may affect health outcomes}

\subsubsection{Learning about health}

Participants explained that the intervention had enabled learning by women's group members: 'This group is very good, I can hear new things, I can meet with friends. . . we have learned lots of things after joining the group' (women's group member, FGD). The women's groups were felt to be a source of support, and a place for learning and sharing knowledge: 'I wish to learn, that is why I come (to the group). Otherwise, we didn't know before that we could get medicine from the health post' (women's group member,
FGD). Group facilitators also felt they had learned and personally developed: 'We have got the chance to learn, as do group members. Before, I only knew that I should be clean, but I didn't know that the baby should also be clean. At that time I was unaware. Anyway, for this third baby, because of the training provided (by MIRA), I did whatever I have learnt. I think I have also changed' (facilitator, interview). Many respondents believed that persons who travelled beyond the immediate village were more likely to have new and different knowledge, and this knowledge should be shared with others: '(Women) should come out of the house and learn things. Whatever we know, we should tell others. We need to share with each other.' (community leader, interview).

\subsubsection{Confidence}

The confidence of group members developed through their involvement with the intervention, and reticence decreased: 'I liked their interaction very much... one or two women were speaking openly... while going to the meeting, I have seen an improvement in women's consciousness' (community leader, interview). The lessening of laaj, a sense of embarrassment or shame, was mentioned repeatedly: 'They were eager to know about things and they were not hesitating to discuss their problems. Those women, who didn't want to talk about their problems before, were interacting with each other' (community leader, interview). A facilitator commented: 'The women of this village didn't talk 
(a)

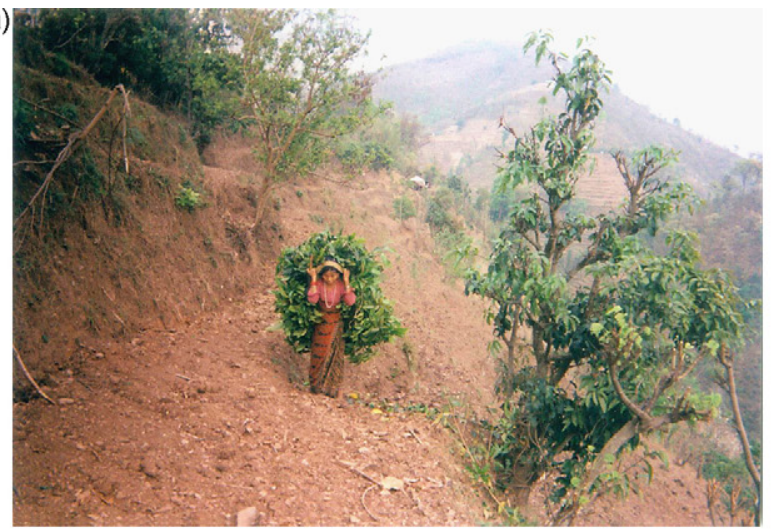

(b)

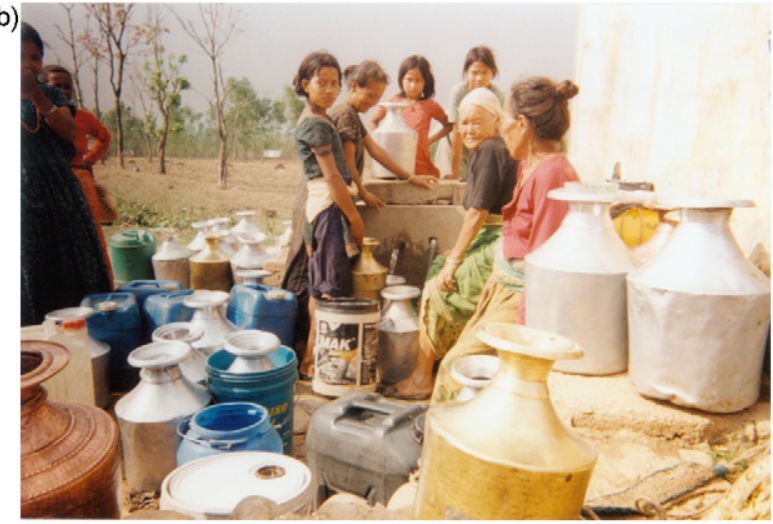

(c)

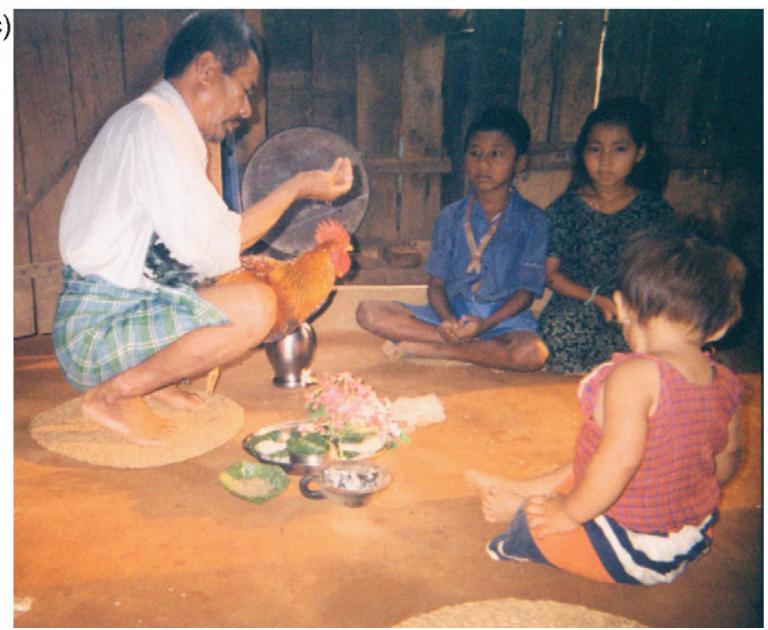

(d)

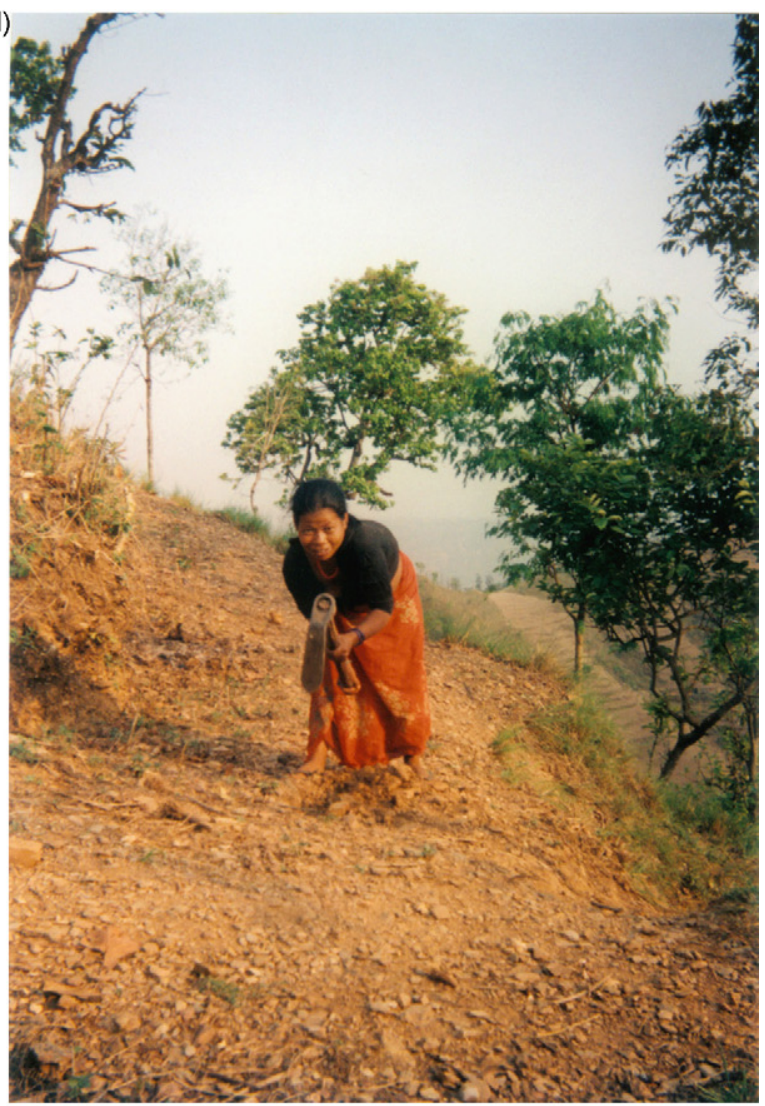

(e)

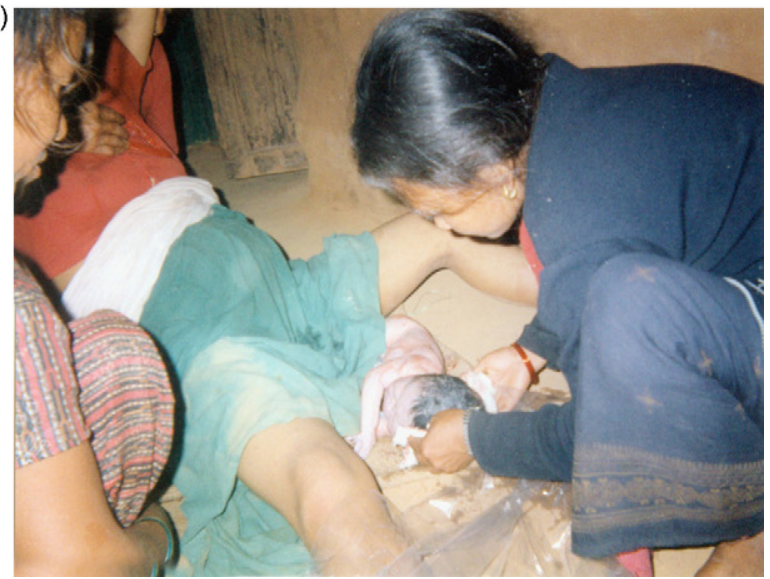

Figure 1. The context of women's lives photographed by respondents.

a. Collection of fodder for livestock; b. Collection of water; c. Shaman performing healing ceremony; d. Woman digging; e. A woman giving birth with a traditional birth attendant.

about pregnancy because they felt embarrassed. They carried heavy loads and bleeding occurred... Now, they meet with us and ask us for help when this happens. They ask without feeling shy' (facilitator, interview). Group discussion and implementation of strategies to address maternal and newborn health problems helped develop confidence, (an example being the management of money through maternal and child health funds): 'Before (we went to the group), we couldn't understand and we couldn't speak prop- erly. Now... if we go to meetings then we can manage things properly' (women's group member, FGD). There was also some evidence that group members challenged household norms, for example when a local girl became pregnant to a boy of another caste, out of wedlock, the group were concerned about how she was being treated: 'They were intercaste, the (mother of the boy) didn't want to let her into the family, and wanted her to abort the baby... all the group members decided to go into her house... now (the girl) 
says that the (mother) doesn't scold her' (facilitator, interview).

\subsubsection{Spreading information about good practice}

Increased knowledge, confidence and encouragement from facilitators stimulated group members to disseminate information about maternal and neonatal health to other women: 'If the baby doesn't suck milk, or breathe, or cry it should be taken to the hospital immediately. We tell (women) everything. Now we are giving training to others' (women's group member, FGD). A health worker also reported increased knowledge about cleanliness at birth: 'Group members have made villagers understand that dirty things affect them. They have even told the villagers to keep the bedding clean before delivery' (health worker, interview).

During interactions with friends and neighbours, women's group members discussed what they had learned in the group: 'We disseminated information to everyone (a)

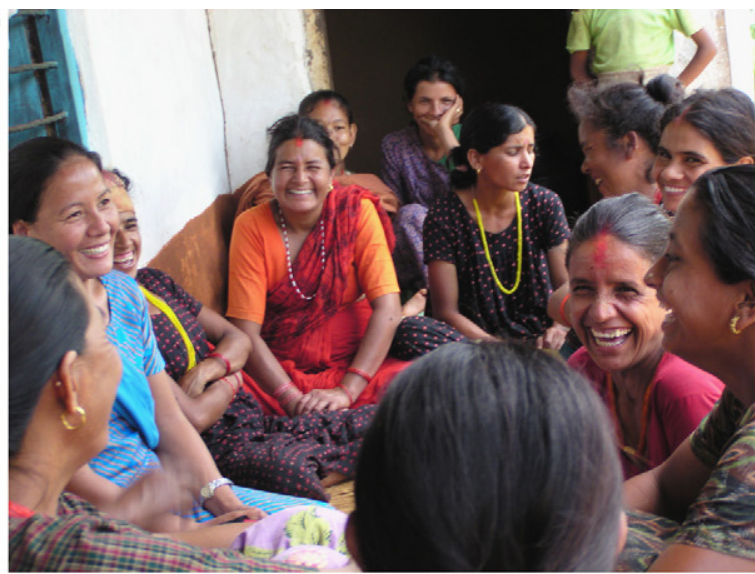

(c)

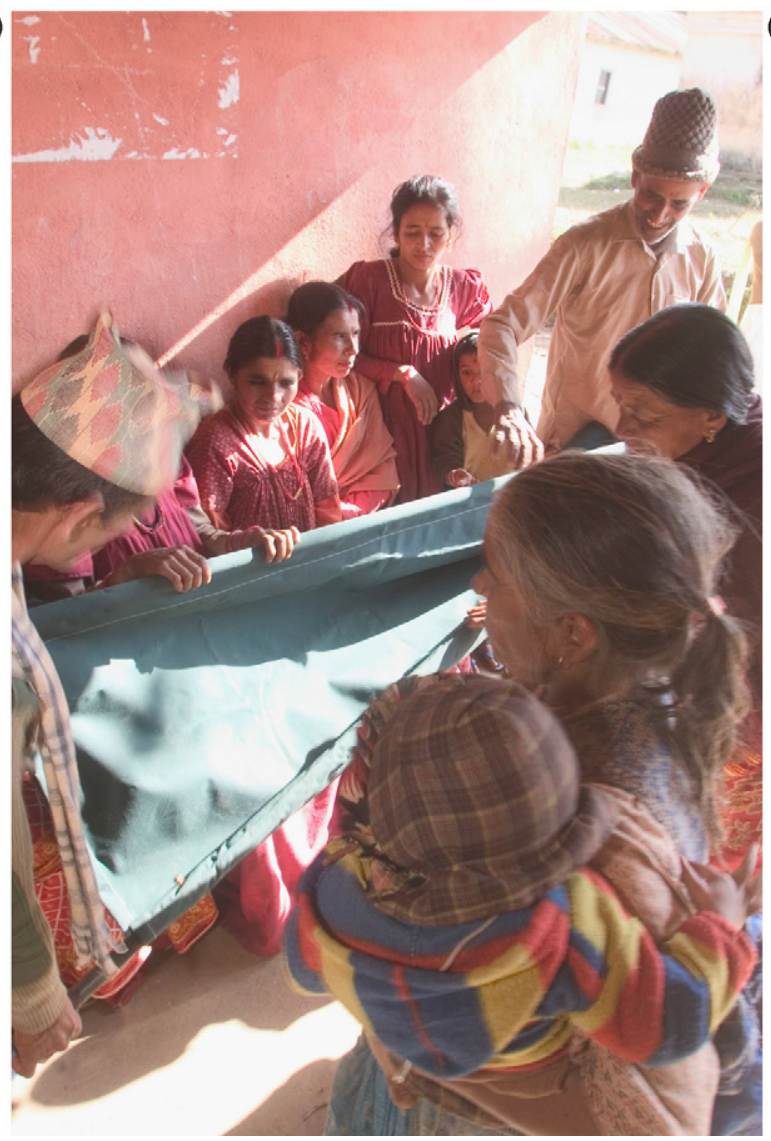

(b)

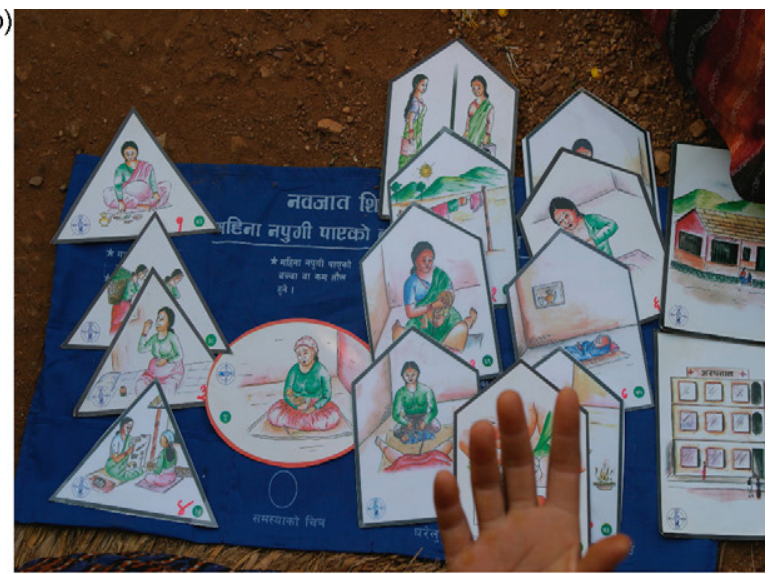

(d)

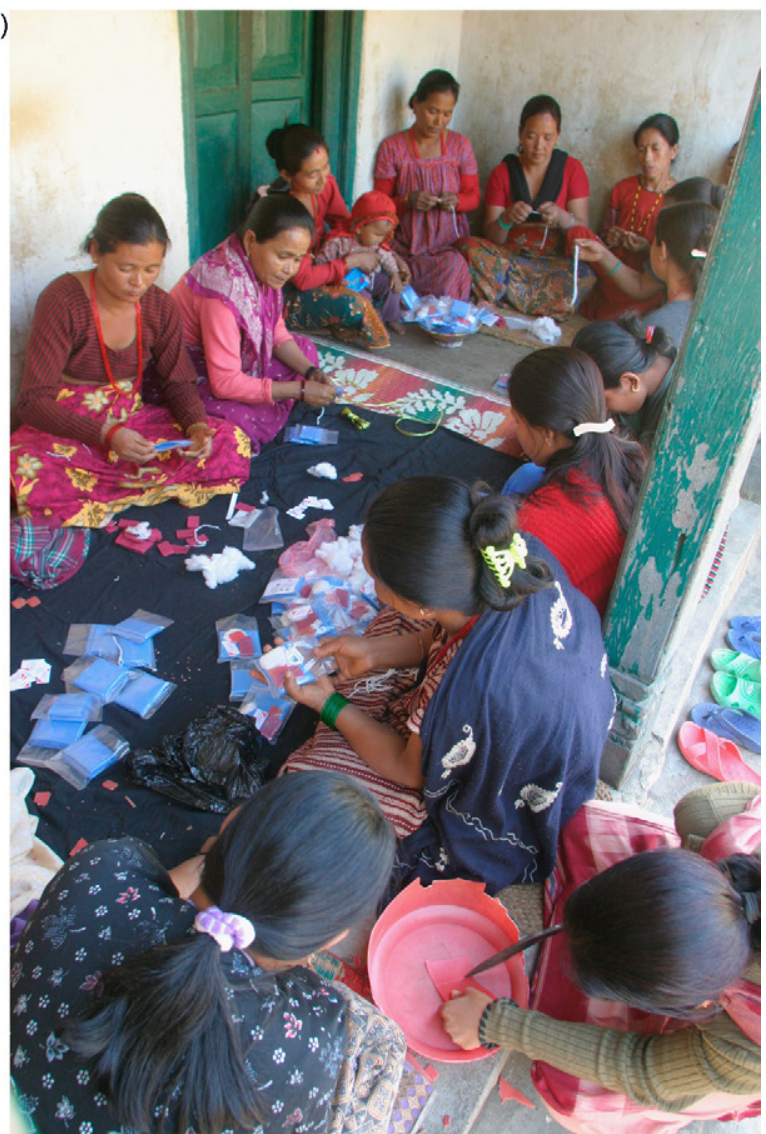

Figure 2. Women's group activities and strategies.

a. Women's group meeting (photograph by Suresh Tamang); b. Picture card game (photograph by Tom Kelly); c. Stretcher scheme (photograph by Tom Kelly); d. Women making clean home delivery kits (photograph by Tom Kelly). 
through the women's group, like tetanus, or whatever the programme is. The group members spread to their neighbours... it is spread out to the community through the group' (facilitator, interview). An example is the dissemination of information about immunisation: 'Now, women's group members give suggestions about immunisation and health. Maybe because of this the numbers of patients have increased. I am very grateful to the women's group members for that' (health worker, interview). Community meetings organised by groups and facilitators also increased awareness about maternal and newborn health: 'They ask "what did you do in the meeting, what did you learn by going to the meeting?" We conducted a ward meeting to make other people understand' (women's group member, FGD).

Groups initiated several strategies to address health problems, including stretcher schemes, revolving funds for obstetric or newborn emergencies, the making and distribution of clean home delivery kits, and the use of picture card games to discuss the causes, prevention and treatment of maternal and newborn problems (Figure $2 \mathrm{a}-\mathrm{d}$ ). Community planning and implementation of strategies to address prioritised problems also enabled dissemination of information. For example, whilst selling clean home delivery kits made by the group, members told families how to maintain cleanliness at birth: 'I give them suggestions, saying "if the delivery kit is used then you won't get caught by diseases"' (women's group member, FGD).

\subsubsection{Community capacity}

Planning and implementation of strategies enabled groups to mobilise community resources and strengthen social networks. Whilst making stretchers, groups approached forest user groups for resources; and whilst gathering money for their fund, they asked other villagers and community groups to contribute: 'The women's group came to ask for money in our meeting on 29th as they didn't have enough money' (women not attending group, FGD). Engagement appears to have strengthened community capacity to address problems, and increased awareness of maternal and neonatal health issues.

Families were concerned about the affordability of care: 'Maybe I thought that it is expensive (to go to the district hospital)' (women's group member, FGD). The women's group funds also addressed concerns about costs incurred reaching and receiving services. ${ }^{27}$ Health care providers and medicine shop owners sometimes gave treatment on credit, and had difficulty recovering this money: '(Medicine shop owner) gives medicine on credit to those who don't have money' (community leader, interview). Resources that villagers could access for their health care needs were scarce, and donations were usually sought from friends, neighbours and money lenders. The women's group fund was considered beneficial because it saved time in emergency situations, was locally available, and did not require dependence on others: 'If the money is kept in the fund, the money is available immediately when it is needed. We don't need to ask other (people)' (men, FGD). The fund enabled families to take decisions independently, without begging from others: 'By bowing down... we need to take a gift to the zamindar's (landlord's) house... instead of doing that if we save money in the fund then we can take out whenever we need' (women's group member, FGD).

Many respondents talked about their lack of proximity to a road or public transport: 'There are problems of transport in (this place), and because of this, the people from (far away) who come for a check-up say, "we will pay money" so you keep expensive medicine there too' (women's group member, FGD). Transporting patients was a problem: 'if the family member becomes sick and they need to take (to hospital) then they need to search for the man to carry, they need to ask for help from the brothers of the village' (women's group member, FGD). Some women's groups managed or bought new stretchers which was seen as a good way to overcome transport difficulties: 'If there is stretcher then it is easy to carry. How can we take the postpartum mother by walking?' (women's group member, FGD). The group and facilitator discussed ways to make them more available to women and villagers: 'We have planned to make another two (stretchers)... one can be used by the people of the higher cluster of houses and one for the people of this cluster' (women's group member, FGD).

The availability of clean home delivery kits made by the groups was a positive incentive to use: '(Pregnant women) are getting (kits) at their home so they say it's good' (women's group member, FGD). Clean home delivery kits were cheap and convenient: 'Before, the thread was cut from many dresses (laughing), no-one ever kept the plastic on the floor... now everything is available in one place. Because it is available people feel good. They feel it is cheap' (facilitator, interview). Local production was valued and the kits were easy to resupply: '(The kit) is good. It will be good for the future. They (women) don't need to ask others. We need to be strong and stand on our own two feet' (community leader, interview). Health volunteers felt that demand for the kits had been created by the women's groups: 'Now in the village people come to ask whether we have delivery kits or not. They didn't know before but now they come to ask (for kits)... some of them go to the market if we don't have (them)' (health volunteer, FGD).

\section{Discussion}

Women in Makwanpur, Nepal, were living in a challenging context of poverty, but were experiencing social change. Women's groups helped them to learn about maternal and newborn health, and to develop their confidence. Groups enabled dissemination of information across communities and built local capacity to take action for better health. Women joining the groups were socioeconomically broadly representative of their communities; groups did not selectively mobilise elite groups or the better-off.

This study had limitations. Due to security concerns, we could not sample areas that were more remote. Respondents may have sought to please the researcher, and may have over-reported expected or socially acceptable behaviours and feelings, thus giving an overly positive projection of the intervention. Stakeholders may also have responded positively to continue receiving the benefits of employment or a further development programme from MIRA. We assured respondents that MIRA could not access 
the raw data, and used an independent consultant to facilitate discussions, to try to minimise this bias. The themes presented here were triangulated by different types of respondents, and were largely undisputed during feedback. Cultural and language differences were addressed by using Nepali research assistants, transcribing the data in Nepali before translation, using a foreign social scientist with good spoken Nepali and personal experience of living in the district for six years, and consulting with the research assistant or translator for clarification when necessary. Both intervention and control areas were experiencing social change over this period and therefore the collection of baseline and longitudinal qualitative data in intervention and control areas would have strengthened the validity of our findings.

The women's group intervention enabled learning among group participants, and in the wider community. Although the intervention was not designed to be a knowledge transfer project, and facilitators were not trained health workers, communities indicated that learning was a strong catalyst for change. The trial baseline study showed some existing knowledge about appropriate care behaviours in the study area, and interactions with group members, facilitators and health workers therefore probably reinforced and increased confidence in existing knowledge. ${ }^{11,12,28}$ A literature review on women's support groups also suggests that increased support and development of confidence through women's group networks can help sustain good health behaviours. ${ }^{29}$

The way that women learnt, especially through the picture card discussions, stimulated group members to disseminate information about maternal and neonatal health to other women informally. Community planning and implementation of strategies to address high priority problems also enabled dissemination of information through mobilisation of community resources and social networks. For example, resources were collected for revolving funds and clean delivery kits, which focused the community on maternal and newborn health, and increased community capacity to address problems. PLA approaches propose that a collective critical consciousness and owned knowledge develops through participation, which enables individuals and communities to become empowered to work towards social change. ${ }^{30,31}$ Our findings support Freire's theories of learning and empowerment through building a critical consciousness. ${ }^{9}$ Other authors have suggested that involvement with community based organisations and increased social networks empowers communities, and leads to better health outcomes. ${ }^{32-36}$ The group process may produce broader understanding of health problems, long-lasting empowerment and development benefit for local communities. The progression through learning, gathering information, gaining self-confidence, developing skills, organising to take action, and taking action, is more empowering than simply receiving messages. Empowered community-based organisations are thought to be the essential link between empowered individuals and effective political action. This dynamic continuum progresses through individual empowerment, small group participation, community organisation and partnership to political action. ${ }^{37}$ The intervention encouraged mobilisation of resources, and groups have linked with their communities to promote newborn and maternal health. Increased access to social networks may have built capacity of communities to work together in addressing problems.

It is of note that there was little evidence of engagement with health services and broader power structures (or improved perceptions of health services), as a result of the intervention. Improvements in newborn survival seem most likely to be related to changes in behaviour within the household and perhaps also in informal as well as formal care-seeking. Planning and implementation of strategies only led to a limited interaction with health service providers. There was some evidence that the intervention helped to revitalise community health volunteers, who often attended the group meetings. Community links with health services may have improved, for example, by sharing information about the availability of services, knowing the identity of health volunteers, and health workers attributing increased service use to the intervention.

The intervention could also be criticised because women's groups did not appear to engage with broader political and social power structures to address social inequality at a higher level. The primary health care movement was also often criticised for achieving small-scale successes, but failing to tackle fundamental national power differentials. ${ }^{38}$ Yet the political context of the intervention, during an insurgency, was a severe constraint to broader political action. This trial was conducted during a time of civil unrest when there had been dissolution of local and national democratic structures. In a more stable political context, groups might stimulate interaction with power structures. $^{39-41}$

Women's groups offer a sustainable and scalable approach to improve child survival. For scale-up, the management of interventions must be effective. The implementing organisation was clearly important in the success of the intervention: the trial team were committed to taking a participatory approach, gained the confidence of communities, disseminated knowledge about maternal and neonatal health, and were perceived as knowledgeable, trustworthy, respected individuals by communities. Communities in intervention areas were also positive and responsive to NGOs, which may have affected the receipt of and response to the intervention. The intervention was feasible and acceptable as maternal and neonatal health was perceived to be the domain of women, and community groups were an accepted way to gain knowledge, personally develop, and help the community progress.

Neonatal mortality rates have fallen slowly but steadily in Nepal, despite the insurgency, but health facilities still struggle to provide basic delivery care services and most women still deliver at home, attended by family or neighbours. ${ }^{2}$ Skilled birth attendants and community empowerment have been identified as priorities to improve maternal and neonatal survival. ${ }^{42} \mathrm{~A}$ key policy research question for the future is how to link community empowerment with increased utilisation of institutional births. There is some evidence that the sensitisation of communities through groups has led to greater awareness of the need to seek delivery care when necessary. Globally, there has been a movement to research the effectiveness 
of community based participatory interventions for newborn and maternal survival. ${ }^{43-45}$ It is important to provide detailed description of community interventions, as this term has been used to describe quite different approaches. Reporting and consideration of context, 'dose' of interventions, and mechanisms by which the intervention is assumed to work are also important to enable explanation of results and demonstrate external validity. ${ }^{5,46}$ Research in rural Bangladesh suggests that group effects on neonatal mortality may be non-significant if the ratio of women's groups to population is not optimum, and the numbers of pregnant women attending groups is lower. ${ }^{45,48}$ The conduct of mixed methods integral process evaluations can help to explain the results of outcome evaluations, and ongoing trials in Malawi, India and Nepal have been collecting process data for this purpose. Data should be collected in both intervention and control areas, and future process evaluations may benefit from specifically researching the empowerment of women and communities, and exploring how, and if, social networks are developed. Collecting longitudinal data over many years would also enable examination of changes over time and the sustainability of change

\section{Conclusion}

The women's group intervention had a significant impact on neonatal mortality, and we have presented evidence that the effect occurred through learning about maternal and newborn health, building the confidence of group members and interaction with communities whilst developing strategies to address problems. Our findings support calls for the integration of process evaluations in randomised controlled trials. ${ }^{47}$ Process evaluation can help to explore trial results, consider the effect of the sociopolitical context, and develop hypotheses about why interventions are successful or unsuccessful. Further work is needed to explore the impact of women's groups in different settings (e.g. urban vs rural, rural Africa compared with Asia), other potential benefits such as empowerment, and mental and sexual health, the constraints and success factors for groups, and to elucidate how a women's group approach can be taken to scale.

Authors' contributions: All the authors contributed to the design of the study and criticised drafts of the paper; JM was responsible for the conception and overall supervision of the qualitative data collection; DSM, KT and his team managed the trial; JM, RN and BB managed the qualitative data collection, data entry and analysis; AS, DO and NP analysed the group socioeconomic status; DO, SH and AC were technical advisers to the study; AC, DO and DM helped design the original trial protocol; $A C$ and JM wrote the first draft of the paper and were responsible for subsequent collation of inputs and redrafting. All authors read and approved the final manuscript. JM and AC are guarantors of the paper.

Acknowledgements: We thank the individuals in Makwanpur district who gave their time generously and without complaint, and the field staff of the MIRA Mak- wanpur team. We would also like to thank Audrey Prost for her comments on a draft of this paper.

Funding: The randomised control trial that this study evaluates was funded by the UK Department for International Development, the World Health Organisation, United Nations Children's Fund, and the United Nations Fund for Population Activities. The funders played no part in the design, collection or analysis of data.

\section{Conflicts of interest: None declared.}

Ethical approval: The trial and process research was approved by the Nepal Health Research Council and the ethics committee of the Institute of Child health and Great Ormond Street Hospital for Children, and was done in collaboration with the Ministry of Health, Nepal. Participation in the study was voluntary, and verbal consent to participate was obtained (as most respondents were illiterate). Data were anonymous and quotes are presented without attribution to respondents. Participants in the photoelicitation exercise were asked to seek permission from subjects before taking their picture. We took verbal consent to see the photographs, keep a copy, and show them in public fora. We assured participants that there would be no direct financial gain from their photographs.

\section{References}

1. Lawn JE, Cousens S, Zupan J. 4 million neonatal deaths: when, where, why? Lancet 2005 March;365(Neonatal Survival Series):9-18.

2. Nepal Ministry of Health and Population. Nepal Demographic and Health Survey. Kathmandu: Population Division, Ministry of Health and Population, Government of Nepal, New Era ORC Macro; 2006.

3. Manandhar DS, Osrin D, Shrestha BP, Mesko N, Morrison J, Tumbahangphe KM, et al. Effect of a participatory intervention with women's groups on birth outcomes in Nepal: a cluster randomised controlled trial. Lancet 2004;364:970-9.

4. Morrison J, Tamang S, Mesko N, Osrin D, Shrestha B, Manandhar M, et al. Women's health groups to improve perinatal care in rural Nepal. BMC Pregnancy Childbirth 2005;5:6.

5. Wight D, Obasi A. Unpacking the black box: the importance of process data to explain outcomes. In: Stephenson J, Imrie J, Bonell C, editors. Effective sexual health interventions, issues in experimental evaluation. Oxford: Oxford University Press; 2003.

6. Howard Grabman L. Planning together: developing community plans to address priority maternal and neonatal health problems in rural Bolivia. In: De Koning K, Martin M, editors. Participatory research in health issues and experiences. London: Zed Books; 1996.

7. Chambers R. Notes for participants in PRA-PLA familiarisation workshops in 2004. Brighton: Institute of Development Studies; 2004.

8. Freire P. Pedagogy of the oppressed. London: Penguin; 1972.

9. Rifkin S, Pridmore P. Partners in Planning. London: Macmillan Education Limited; 2001.

10. HMG Nepal. Population Census 2001. Kathmandu: Central Bureau of Statistics; 2002

11. Mesko N, Osrin D, Tamang S, Shrestha B, Manandhar D, Manandhar $\mathrm{M}$, et al. Care for perinatal illness in rural Nepal: a descriptive study with cross-sectional and qualitative components. BMC Int Health Hum Rights 2003;3:3.

12. Osrin D, Tumbahangphe K, Shrestha D, Mesko N, Shrestha B, Manandhar $\mathrm{M}$, et al. Cross sectional, community based study of care of newborn infants in Nepal. BMJ 2002;325:1063-6.

13. Osrin D, Mesko N, Shrestha B, Shrestha D, Tamang S, Thapa S, et al. Reducing childhood mortality in poor countries. Trans $R$ Soc Trop Med Hyg 2003;97:1-4.

14. Collier J. Visual Anthropology: photographs as a research method. New York: Holt, Reinhart, Winston; 1967.

15. Wang C, Burris MA. Photovoice: concept, methodology, and use for participatory needs assessment. Health Ed Behaviour 1997;24:369-87. 
16. Wang C, Ling YY, Ling FM. Photovoice as a tool for participatory evaluation: the community's view of process and impact.J Contemp Health 1996;4:47-9.

17. Graziano K. Oppression and resiliency in a post-apartheid South Africa: unheard voices of black gay men and lesbians. Cultur Divers Ethnic Minor Psychol 2004;10:302-16.

18. Morrow V. Using qualitative methods to elicit young people's perspectives on their environments: some ideas for community health initiatives. Health Educ Res 2001;16:255-68.

19. Ogilvie M, Ryan M. A sense of home. Melbourne, Australia: ANZMAC; 2002.

20. Gallo M. Picture this: immigrant workers use photography for communication and change. J Workplace Learn 2002;14:49-57.

21. Hubbard J. Shooting back: a photographic view of life by homeless children. San Francisco, CA: Chronicle Books; 1991.

22. Hagedorn M. Hemeneutic photography: an innovative aesthetic technique for generating data in nursing research. Adv Nurs Sci 1994;17:44-50.

23. Thoutenhoofd E. Method in a photographic enquiry of being deaf. Sociol Res Online 1998;3(2).

24. Wang C, Burris MA, Ping XY. Chinese village women as visual anthropologists: a participatory approach to reaching policy makers. Soc Sci Med 1996;42:1391-400.

25. Gold S. Israeli immigrants in the United States: the question of community. Qual Sociol 1994;17:325-63.

26. Ritchie J, Spencer L. Qualitative data analysis for applied policy research. In: Bryman A, Burgess R, editors. Analysing qualitative data: London: Routledge; 1994.

27. Morrison J, Thapa R, Sen A, Neupane R, Borghi J, Tumbahangphe K, et al. Utilisation and management of maternal and child health funds in rural Nepal. Community Dev J 2008, doi:10.1093/cdj/bsn029.

28. Tamang S, Mesko N, Shrestha B, Osrin D, Manandhar M, Standing H, et al. A qualitative description of perinatal care practices in Makwanpur District, Nepal. Contrib Nepalese Stud 2001;28:10-9.

29. Green CP. Mother Support Groups: A Review of Experience in Developing Countries. Arlington, VA: U.S. Agency for International Development, by the Basic Support for Institutionalizing Child Survival (BASICS) Project; 1998.

30. Baum F. Participatory action research. J Epidemiol Community Health 2006:60:854-7.

31. Tandon R. The historical roots and contemporary tendencies in participatory research: implications for health care. In: De Koning K, Martin M, editors. Participatory research in health: issues and experiences. London: Zed Books; 1996.

32. Rosato M, Laverack G, Howard Grabman L, Tripathy P, Nair $\mathrm{N}$, Mwansambo C, et al. Community participation: lessons for maternal, newborn, and child health. Lancet 2008;372: 962-71.

33. Wallerstein N. Powerlessness, empowerment, and health: implications for health promotion programmes. Am J Health Promot 1992;6:197-205.

34. Labonte R. Empowerment: notes on professional and community dimensions. Can Rev Soc Policy 1990;26:64-75.

35. Rissel C. Empowerment: the holy grail of health promotion? Health Promot Int 1994;9:39-47.

36. Laverack G. Health promotion practice: building empowered communities. Maidenhead, Berkshire: Open University Press; 2007.

37. Laverack G. An identification and interpretation of the organizational aspects of community empowerment. Community Dev J 2001;36:134-45

38. Rifkin S. Paradigms Lost: toward a new understanding of community participation in health programmes. Acta Trop 1996;61:79-92.

39. Woelk GB. Cultural and structural influences in the creation of and participation in community health programmes. Soc Sci Med 1992;35:419-24.

40. Walt G, Perera M, Heggengougen K. Are large-scale volunteer community health workers programmes feasible? The case of Sri Lanka. Soc Sci Med 1989;29:599-608.

41. Zakus DL, Lysack C. Revisiting community participation. Health Policy Plan 1998;13:1-12.

42. Costello A, Filippi V, Kubba T, Horton R. Research challenges to improve maternal and child survival. Lancet 2007;369:1240-3.

43. Towards 4+5.org.uk. London: Towards 4+5; (C2006 [updated 2009]. www.towards4and5.org.uk [accessed 13 June 2009].

44. Bhutta ZA, Darmstadt GL, Hasan BS, Haws RA. Community based interventions for improving perinatal and neonatal health outcomes in developing countries: a review of the evidence. Pediatrics 2005;115:519-617.

45. Baqui AH, El Arifeen S, Darmstadt GL, Ahmed S, Williams E, Seraji H, et al. Effect of community-based newborn-care intervention package implemented through two service-delivery strategies in Sylhet district, Bangladesh: a cluster-randomised controlled trial. Lancet 2008;371:1936-44.

46. Hawe P, Sheill A, Riley T, Gold L. Methods for exploring implementation variation and local context within a cluster randomised community intervention trial.J Epidemiol Community Health 2004;58:788-93.

47. Oakley A, Strange V, Bonell C, Allen E, Stephenson J. Process evaluation in randomised controlled trials of complex interventions. BMJ 2006;332:413-6

48. K. Azad et al., unpublished data. 